\title{
Preparing Students for an International Career: The Case for Contextualizing and Integrating Ethics Education
}

\author{
Sue Wright ${ }^{1}$, Maria Cadiz Dyball ${ }^{2}$, Philippa Byers ${ }^{3} \&$ Renee Radich ${ }^{2}$ \\ ${ }^{1}$ Department of Applied Finance and Actuarial Studies, Macquarie University, NSW, Australia \\ ${ }^{2}$ Department of Accounting and Corporate Governance, Macquarie University, NSW, Australia \\ ${ }^{3}$ Department of Philosophy, Macquarie University, NSW, Australia \\ Correspondence: Sue Wright, Department of Applied Finance and Actuarial Studies, Macquarie University, \\ NSW 2109, Australia. Tel: 61-2-9850-8521. E-mail: sue.wright@mq.edu.au
}

Received: August 21, 2012

doi:10.5539/ass.v8n14p97
Accepted: September 24, 2012 Online Published: October 31, 2012

URL: http://dx.doi.org/10.5539/ass.v8n14p97

\begin{abstract}
A key aim of IFAC (International Federation of Accountants)'s International Education Standard 4 (IES4) is to raise the ethical awareness of candidates preparing for careers as accounting professionals. This paper reports the results of a survey of undergraduate accounting students at an Australian university, and develops an approach for the implementation of IES4 in business schools with culturally diverse student populations. The survey asks students at different stages of their programs about the contribution of tertiary education to their ethical ideas, drawing conclusions based on their culture, year of study, career intentions, age and gender. It then suggests ways of teaching ethics that value and integrate students' diverse experiences and cultural backgrounds, as well as their existing knowledge. Such initiatives could expand the horizons of students from all cultural backgrounds by increasing their cultural sensitivity and awareness of ethics as an issue of relevance to their professional careers.
\end{abstract}

Keywords: ethics education, international education standard 4

\section{Introduction}

Financial scandals focus attention and galvanize public opinion (Griffith, 2006). In recent years a heightened interest in the connections between accounting and ethics has arisen due to the global financial crisis and, before that, the rapid and dramatic collapse of the international accounting firm of Arthur Andersen and its association with the demise of giant, global companies including Enron and WorldCom (Jennings, 2004; Molyneaux, 2004). The accounting profession's response has been to propose a model of individual or self-regulation. This is supported through certain institutions, programs, and structures within the profession (Brien, 1998, p. 391); an important one being the accreditation of education programs, with express specifications to include ethics, by professional accounting associations that are members of The International Federation of Accountants (IFAC).

IFAC has prescribed eight International Education Standards (IES1 to IES8). IES 4: Professional Values, Ethics and Attitudes, effective January 1, 2005 (IFAC, 2008), requires IFAC members to devote a portion of undergraduate accounting programs, or prequalification stage programs, to developing students' professional values, ethics, and attitudes. Thus through its influence on the accreditation process of educational programs by its member accounting associations, IES 4 directly influences the structure and content of accounting education programs. As a supplement to IES 4, IFAC has also released a practice statement for member bodies-IEPS 1: Approaches to Developing and Maintaining Professional Values, Ethics, and Attitudes (IFAC, 2007). IFAC's recommendations, including IES 4 and IEPS 1, are currently being addressed by 159 member bodies representing 124 countries (IFAC, 2010).

IFAC recommends that prequalification accounting programs focus on accounting students' acquisition of ethical knowledge, sensitivity and decision-making ability in a three-staged approach. Stage 1 teaches traditional ethical theories developed and articulated within the Western philosophical tradition. Stage 2 introduces ethical issues as they apply within accounting contexts, with the aim of raising students' sensitivity to the ethical dimensions of professional practice while applying the theoretical content delivered in Stage 1. Stage 3 builds on the previous stages, by introducing more complex or situated cases. The aim of Stage 3 is to foster capacities for professional 
decision-making and judgment.

In general, accounting educators have responded to repeated calls to include ethics education within accounting programs, and there is considerable research that shows that the inclusion of ethics education can inculcate in accounting students a strong sense of ethics as professional accountants (e.g. Molyneaux, 2004; Jennings, 2004; Armstrong et al., 2003; MacFarlane, 1998; Leung \& Cooper, 1995; Ponemon, 1993). However, each individual's ethical perspective or orientation is related to gender, level of education, religious conviction, and work experience (Craig Keller et al., 2007, p. 305) (Note 1), and so ethics education needs to be implemented in ways that are culturally sensitive and inclusive.

IFAC acknowledges the breadth of its international reach, and recognises the need to contextualise the three-staged approach to ethics education for different educational settings and different student cohorts. For example, an IFAC-commissioned Ethics Education Toolkit notes that a single curriculum is not suitable across all student cohorts, and that cultural and other differences are often present within single educational settings (Cooper et al., 2008, p. 416). The latter issue was the focus of a research project undertaken to investigate implementing IFAC's three-staged approach at a university (like ours) with a culturally mixed student cohort, one aspect of which is reported in this paper.

The first stage in the project reviewed the ethics education currently included within our own accounting program and found that with some relatively minor modifications, the three-stage approach could be implemented, but that closer attention to the cultural sensitivity and inclusiveness of the current offering was warranted. This review was specific to our university and is not reported here. Mindful that even minor modifications to the accounting program would require the co-operation of staff, we then interviewed teaching staff to understand their attitudes to the inclusion of ethics in the accounting program (reported in Wright et al., 2011). We determined that staff would like to be equipped to confidently deliver ethics content and to have material relevant to a technically-focused student cohort. We suggested that one means of overcoming these potential barriers might be to involve academics from other discipline areas, such as philosophy, in developing and delivering foundational material early in the curriculum and having accounting staff teach applications of this material in the latter two stages.

The final part of our project, reported in this paper, focused on the cultural mix of the students undertaking the accounting program at our university, which is not dissimilar to that of accounting student cohorts at many other Australian universities, and indeed at universities in many other countries. We developed a survey to identify whether culture, gender and experience influence students' views on ethics, ethics education and the accounting profession's ethical responsibilities. Our results are in line with other findings that ethical perspectives and opinions are related to gender, level of education, religious conviction, and work experience (Craig Keller et al., 2007, p. 305). (Note 1)

Rather than viewing the cultural mix of the student cohort and the diversity of their opinions as a barrier or difficulty for implementing IFAC's three-staged approach to ethics education, or indeed, for other aspects of accounting education, we focused on the potential advantages. We believe that engaging with a spread of cultural, political and moral perspectives during accounting studies helps students understand that these factors affect the context, representation and resolution of ethical issues within their work places (Waldmann, 2000, p. 24) and also prepares students for an increasingly globalised business environment and potential international careers in accounting. Accordingly, we drew on the survey findings to make practical recommendations for implementing IFAC's three-staged approach in a culturally sensitive and inclusive manner that expressly engages with the range of opinions and ideas that are present within a mixed student cohort.

The remainder of the paper is organized into four parts. Part 2 describes the student survey. Part 3 presents the findings of the student survey. Part 4 makes recommendations for implementing IFAC's three-staged approach to ethics education at universities with mixed student cohorts. Our concluding remarks are in Part 5.

\section{Method}

The aim of this research is to investigate the ethical awareness and expectations of a culturally mixed prequalification accounting student cohort, and to use those findings to develop recommendations for implementing IFAC's three-stage ethics education recommendations at universities (like ours) with mixed student cohorts. In our view, a culturally sensitized and inclusive approach to teaching ethics within accounting education programs will best prepare students from all backgrounds for international careers in accounting.

We use a survey approach to determine the influences of culture, gender and experience influence students' views on ethics, ethics education and the accounting profession's ethical responsibilities. (Note 2) We developed 
a survey instrument to identify (i) cultural, gender and experiential variations in factors that influence students' views about ethics, (ii) variations in students' awareness and expectations of the accounting profession's ethical obligations over the course of their studies, and, (iii) variations in students' views about the inclusion of ethics within the accounting program.

The survey is anonymous, and was administered to undergraduate accounting students at our university. The specific information the survey collected is (i) non-identifying demographic details including cultural background, gender, career intentions and level of study, (ii) students' views on the sources of their own ethical ideas, (iii) students' views on the ethics education currently included in the undergraduate program, and (iv) students' views on their awareness and expectations of the accounting profession's ethical responsibilities.

The survey is designed for completion within 15 minutes in a lecture setting. The survey content, layout and design incorporates feedback from colleagues in professional education, developmental psychology and accounting education. It was piloted on a small number of accounting teaching staff, who come from a range of cultural backgrounds. All survey questions can be completed by ticking an appropriate box, with the exception of the final open-ended question.(Note 3) The survey includes a covering letter for students explaining its purpose. University Ethics Committee approval was obtained.

The survey was administered to students attending lectures in three core accounting subjects; one at each year of the three year program. The survey was also administered to students at a feeder college for the university's accounting program.(Note 4) The populations of students at the university and feeder college at the time of the survey were 2141 and 710 respectively (2851 in total). There are 1503 useable surveys (response rate 52.72\%). Responses are analyzed separately by cultural background, gender and credit points completed. This allowed us to measure the gender and cultural mix of students within the accounting program, and to assess differences between students of different cultural backgrounds and gender. The construct of cultural background is measured by citizenship, self-identified cultural background, and language spoken at home. The inclusion of credit points completed allows us to analyze changes in students' ideas as they advance through year levels of the accounting program. Students' career intentions are measured with questions concerning intentions to complete a pre-qualification major in accounting and intentions to obtain professional accounting qualifications.

\section{Findings}

\subsection{Demographics}

Relevant demographic data for all students in the sample and by credit points completed/year of their study(Note 5) are presented in Table 1. There is no significant difference between the proportions of total males $(51.6 \%)$ and females (48.4\%) with only slight differences across the years of study. Overall, close to half of the students are younger than 21 years $(45.2 \%)$, with only $4 \%$ older than 30 years. $19.25 \%$ of students are under 21 in their final year.

Table 1. Demographic information

\begin{tabular}{llrrrr}
\hline Question & $\begin{array}{l}\text { Response } \\
\text { options }\end{array}$ & \multicolumn{4}{c}{ Percentage response (\%) } \\
\cline { 3 - 6 } & & $\begin{array}{r}\text { Total } \\
\mathbf{n}= \\
1503\end{array}$ & $\begin{array}{l}\text { Less than 24 } \\
\text { credit points } \\
\mathbf{( 4 1 . 5 2 \% )}\end{array}$ & $\begin{array}{l}\text { 24-47 credit } \\
\text { points } \\
\mathbf{( 4 0 . 7 9 \% )}\end{array}$ & $\begin{array}{l}\text { 48 or more } \\
\text { credit points } \\
(\mathbf{1 7 . 7 0 \% )}\end{array}$ \\
\hline Gender & Male, & 51.68 & 49.59 & 53.83 & 51.50 \\
Age & Female & 48.32 & 50.41 & 46.17 & 48.50 \\
& $<21$ years, & 45.23 & 62.02 & 39.34 & 19.25 \\
& 21-30 years, & 50.77 & 35.42 & 56.72 & 73.21 \\
& 31-40 years, & 2.47 & 0.96 & 2.30 & 6.42 \\
Enrolment & $>$ 40 years & 1.53 & 1.60 & 1.64 & 1.13 \\
& full-time, & 91.68 & 90.38 & 93.96 & 89.47 \\
Current Level of Paid & part-time & 8.32 & 9.62 & 6.04 & 10.53 \\
Employment & 0 hours, & 5.06 & 4.81 & 4.57 & 6.77 \\
& $<10$ hours, & 54.29 & 57.85 & 52.20 & 50.75 \\
& 11-20 hours, & 32.14 & 29.97 & 35.89 & 28.57 \\
& $>20$ hours & 8.52 & 7.37 & 7.34 & 13.91
\end{tabular}




\begin{tabular}{llrrrr} 
Citizenship & Australian, & 25.22 & 22.28 & 23.98 & 34.96 \\
Cultural Background & Other & 74.78 & 77.72 & 76.02 & 65.04 \\
& Australian, & 9.85 & 10.90 & 7.99 & 11.65 \\
& Chinese/Hong & 61.54 & 61.70 & 60.52 & 63.53 \\
& Kong, & 7.45 & 8.01 & 8.32 & 4.14 \\
& Korean, & 21.16 & 19.39 & 23.16 & 20.68 \\
& Other & & & & \\
Language Spoken at & English, & 16.97 & 16.35 & 16.15 & 20.30 \\
Home & Chinese, & 52.89 & 53.21 & 52.37 & 53.38 \\
& Korean, & 6.52 & 7.21 & 7.18 & 3.38 \\
& Other, & 12.91 & 12.50 & 13.70 & 12.03 \\
& Two languages & 10.71 & 10.74 & 10.60 & 10.90 \\
Complete a major in & yes, & 90.22 & 84.89 & 93.46 & 94.72 \\
accounting & no & 9.78 & 15.02 & 6.54 & 5.28 \\
$\begin{array}{l}\text { Obtain a professional } \\
\text { accounting }\end{array}$ & yes, & 83.30 & 80.83 & 85.55 & 83.78 \\
qualification & no & 16.70 & 19.17 & 14.45 & 16.22 \\
$\begin{array}{l}\text { Pursue a professional } \\
\text { accounting career }\end{array}$ & yes, & 83.68 & 80.33 & 85.79 & 86.59 \\
\hline
\end{tabular}

Demographic data for all students in the sample and by credit points completed/year of their study

Over $90 \%$ of the students are enrolled full-time, an attribute which holds consistently across all years of study, although it is slightly higher for students who are at the second year stage of their studies, and slightly lower for students in their final year. Equal proportions of students in the sample are in first year and second year, with only $17.7 \%$ of students in their final year. The majority of students $(59.4 \%)$ do not undertake more than 10 hours of paid employment per week, and only $8.5 \%$ of students undertake more than 20 hours of paid employment. This is consistent with the low rate of part-time enrolment. The proportion of students working longer hours increases through the stages of study, with more of the second year students working between 11 and 20 hours per week, compared to first year students, and with more of the final year students working more than 20 hours per week compared to the earlier stage students.

The cultural spread of the student population studying accounting at our university is clear. Given the multi-cultural nature of Australia's population, three measures are used to describe culture: citizenship, cultural background and language spoken at home.(Note 6) The use of multiple measures for this construct is justified by the results which show that while $25.2 \%$ report their citizenship as Australian, only $9.9 \%$ identify Australian as their cultural background and only 17\% report English as the main language spoken at home.(Note 7) Six choices were given for cultural background (Australian, Chinese, Indonesian, Indian, Thai and other) with space to specify other if desired. $61.5 \%$ of students reported a Chinese/Hong Kong cultural background and $7.5 \%$ specified Korean. Other cultural backgrounds (for example students from Bangladesh, India, Indonesia, Japan, Malaysia, Sri Lanka, Thailand, Vietnam and Western Europe) aggregate to $21.2 \%$. While their cultural background does not differ across their years of study, more final year students are Australian citizens (35\%) and the proportion of students speaking English at home increases to $20.3 \%$. The majority of students speak a Chinese language at home (52.9\%). Interestingly, $10.7 \%$ of students reported speaking two languages at home. This diversity of language is considered in the discussion of the implications of our results.

Accounting is the intended area of degree major and employment for the overwhelming majority of students: $89.9 \%$ intend to complete an accounting major, and over $83 \%$ intend to obtain a professional accounting qualification and pursue a professional accounting career. This holds over the period of study with final year students indicating that almost $95 \%$ intend to complete an accounting major and $86 \%$ intend to pursue a professional accounting career.

The student survey was designed to assist us in understanding students' pre-existing ethical ideas, and their views on the study of ethics. Results of analysis of these issues are provided in the following sections.

\subsection{Sources of Ethical Ideas}


The sources of students' views on ethics are presented in Table 2. Considering the student body as a whole, family is the source of ideas on ethics that has "a lot" of influence for the highest percentage of students $(71.32 \%)$, followed by cultural background $(46.66 \%)$ and university education $(39.2 \%)$. The sources that have "a lot" of influence on the lowest percentages of students are religion, the workplace and the professional code of ethics, with $29.9 \%, 26.21 \%$ and $22.71 \%$ respectively.

Table 2. Students' sources of ideas on ethics

\begin{tabular}{|c|c|c|c|c|c|c|c|c|c|c|c|c|c|c|}
\hline \multirow{2}{*}{$\begin{array}{l}\text { Significant } \\
\text { Differences } \\
\text { (p value) }\end{array}$} & \multirow[t]{2}{*}{ Response } & \multicolumn{5}{|c|}{ Cultural Background } & \multicolumn{3}{|c|}{ Gender } & \multicolumn{4}{|c|}{ Credit Points Completed } & $\begin{array}{l}\text { Total } \\
(\%)\end{array}$ \\
\hline & & $\begin{array}{c}\text { Australian } \\
\text { (\%) }\end{array}$ & $\begin{array}{c}\text { Chinese/ } \\
\text { Hong } \\
\text { Kong } \\
(\%)\end{array}$ & $\begin{array}{c}\text { Korean } \\
\text { (\%) }\end{array}$ & $\begin{array}{c}\text { Other } \\
\text { (\%) }\end{array}$ & p-value & $\begin{array}{l}\text { Male } \\
(\%)\end{array}$ & $\begin{array}{c}\text { Female } \\
\text { (\%) }\end{array}$ & p-value & $\begin{array}{c}\text { Less } \\
\text { than } \\
24 \\
(\%)\end{array}$ & $\begin{array}{r}24-47 \\
(\%)\end{array}$ & $\begin{array}{l}48 \text { or } \\
\text { more } \\
(\%)\end{array}$ & p-value & \\
\hline \multirow[t]{3}{*}{ Family } & Not at all & 2.76 & 6.01 & 2.78 & 2.91 & & 4.27 & 5.34 & & 6.38 & 3.56 & 3.85 & & 4.79 \\
\hline & A little & 14.48 & 27.81 & 15.74 & 19.74 & 0.000 & 21.47 & 26.44 & 0.038 & 24.22 & 22.37 & 26.54 & 0.092 & 23.89 \\
\hline & A lot & 82.76 & 66.18 & 81.48 & 77.35 & & 74.27 & 68.21 & & 69.39 & 74.07 & 69.62 & & 71.32 \\
\hline \multirow[t]{2}{*}{ Friends } & Not at all & 4.17 & 9.70 & 5.61 & 8.47 & & 6.39 & 10.88 & & 10.40 & 6.34 & 9.41 & & 8.58 \\
\hline & A little & 56.94 & 62.91 & 67.29 & 53.42 & 0.001 & 63.04 & 58.19 & 0.007 & 59.74 & 60.45 & 63.14 & 0.074 & 60.62 \\
\hline Religion & A lot & 27.97 & 24.54 & 30.84 & 51.31 & & 31.73 & 30.33 & & 28.36 & 32.36 & 34.68 & & 31.09 \\
\hline Cultural & Not at all & 15.60 & 7.49 & 5.56 & 9.74 & & 7.54 & 9.76 & & 11.42 & 6.62 & 6.59 & & 8.61 \\
\hline \multicolumn{15}{|l|}{ Background } \\
\hline & A little & 51.06 & 43.74 & 46.30 & 44.16 & 0.005 & 40.24 & 49.50 & 0.000 & 47.52 & 43.97 & 39.92 & 0.001 & 44.73 \\
\hline & A lot & 33.33 & 48.77 & 48.15 & 46.10 & & 52.22 & 40.74 & & 41.06 & 49.41 & 53.49 & & 46.66 \\
\hline \multirow[t]{3}{*}{ Workplace } & Not at all & 23.24 & 28.11 & 21.90 & 23.59 & & 24.52 & 27.98 & & 31.83 & 23.49 & 19.03 & & 26.21 \\
\hline & A little & 51.41 & 53.83 & 63.81 & 49.83 & 0.007 & 55.51 & 51.36 & 0.241 & 51.59 & 53.71 & 57.49 & 0.000 & 53.48 \\
\hline & A lot & 25.35 & 18.06 & 14.29 & 26.58 & & 19.97 & 20.66 & & 16.58 & 22.80 & 23.48 & & 20.31 \\
\hline University & Not at all & 26.57 & 4.45 & 14.15 & 14.15 & & 5.73 & 13.28 & & 10.31 & 8.83 & 8.49 & & 9.39 \\
\hline \multicolumn{15}{|l|}{ Education } \\
\hline & A little & 43.57 & 54.65 & 65.38 & 52.48 & 0.000 & 56.45 & 51.22 & 0.000 & 52.95 & 55.36 & 52.63 & 0.028 & 53.88 \\
\hline & A lot & 16.43 & 25.26 & 16.35 & 23.76 & & 25.80 & 20.95 & & 20.74 & 24.05 & 28.34 & & 23.41 \\
\hline
\end{tabular}

Student responses to the question, What is the source of your ethical ideas? Overall, by cultural background, by gender and by credit points completed.

However, this pattern is not consistent across culture, gender, or the years of study completed. When examined cross culturally, the factors that influence students' ideas on ethics are significantly different $(p<.01)$ for all aspects considered. For students with an Australian cultural background, the strongest influences are family and friends followed by culture. Religion, workplace, university education and the professional code of ethics has less influence. In contrast, for students with a Chinese cultural background, while the influence of family and friends is strong it is less than for Australian students and the influence of culture is stronger. Most notably, Chinese students regard university education and the professional code as having a far greater influence than do Australian students. This may reflect that the degree is taught in a Western context and therefore is likely to have more impact on students from an Eastern cultural background than local, pre-dominantly Western-educated students. 
Korean cultural background students are similar to Australian students in terms of a strong influence from family and religion and a slightly lower influence from friends. Koreans, as for the Chinese, indicate a higher influence from their cultural background and lower influence of the workplace. Korean students fall between Australian and Chinese students with respect to university education and the professional code of ethics. For the other cultures the primary deviation from these patterns is for religion, with students from other cultures indicating that religion has a stronger influence compared to Australian, Chinese or Korean students.

The effects of gender indicate that the females' sources of ideas on ethics are statistically different to their male counterparts for family $(\mathrm{p}=0.038)$, friends $(\mathrm{p}=0.007)$, cultural background $(\mathrm{p}=0.000)$, university education $(\mathrm{p}=$ $0.000)$ and codes of ethics $(\mathrm{p}=0.000)$. There is no statistical difference in the influence of religion or workplace. Females give lower scores overall which may indicate a reluctance to score any item highly; in other words, they seem to be more conservative in their scoring.

Finally, as the length of study increases, the influence of family, friends and religion remains similar, but there is a significant increase in the influence of cultural background $(p=0.001)$, the workplace $(p=0.000)$, university education $(\mathrm{p}=0.037)$ and the code of professional ethics $(\mathrm{p}=0.028)$. As students have increasing levels of exposure to the workplace (Note 8 ), university and the professional code of ethics, the influence of these factors would be expected to increase. Surprisingly, the influence of culture increases despite the majority of these students living in Australia and away from their culture of origin. It is not possible for us to determine the reasons for this increase, although possible explanations are recognition of the importance of their own background culture to them; or an increased awareness of the variety of cultural influences on ethical decisions due to their exposure to a different, and possibly more multicultural environment.

\subsection{Views on the Study of Ethics}

The students' views on ethics are presented in Table 3, Panels A and B. Descriptive statistics for their overall responses are presented in Panel A. The responses were analyzed using nominal logistic regressions, to estimate which of their demographic factors are more significantly associated with the students' views on ethics. Only three of the five logistic regressions were significant, and so the results of those (with all explanatory variables and with reduced sets of significant explanatory variables) are presented in Panel B and discussed below.

Table 3. Students' views on the study of ethics

Panel A: Overall descriptive statistics for all students

\begin{tabular}{lrrr}
\hline \multicolumn{1}{c}{ Question } & (1) Disagree (\%) & (2) Agree (\%) & (3) Strongly agree (\%) \\
\hline 1. Relevant to accounting degree & 5.24 & 62.52 & 32.24 \\
2. Prepared for workplace & 5.51 & 69.30 & 25.19 \\
3. Encouraged to think ethically & 8.91 & 66.83 & 24.27 \\
4. Familiar with standards & 17.55 & 68.84 & 13.61 \\
& (1) Too little (\%) & (2) Just right (\%) & (3) Too much (\%) \\
5. Emphasis on ethics & 15.45 & 78.02 & 6.52 \\
\hline
\end{tabular}

Student responses to questions on their study of ethics at university

Panel B: Logistic regression results

\begin{tabular}{|c|c|c|c|c|c|c|c|c|c|c|c|}
\hline \multirow{2}{*}{$\begin{array}{c}\text { Model } \\
\text { Details, } \\
\text { p-value } \\
\text { (odds ratio) } \\
\mathrm{n}=1034\end{array}$} & \multirow[t]{2}{*}{$\begin{array}{l}\text { Measurement of } \\
\text { independent } \\
\text { variable }\end{array}$} & \multicolumn{2}{|c|}{$\begin{array}{l}1 \text { Relevance of } \\
\text { ethics to degree }\end{array}$} & \multicolumn{2}{|c|}{$\begin{array}{l}2 \text { Prepared for } \\
\text { ethical issues in } \\
\text { workplace }\end{array}$} & \multicolumn{2}{|c|}{$\begin{array}{c}3 \text { University } \\
\text { encourages me } \\
\text { to think } \\
\text { ethically }\end{array}$} & \multicolumn{2}{|c|}{$\begin{array}{l}4 \text { Familiar with } \\
\text { ethical } \\
\text { standards }\end{array}$} & \multicolumn{2}{|c|}{$\begin{array}{c}5 \text { Emphasis on } \\
\text { ethics at } \\
\text { university }\end{array}$} \\
\hline & & $\mathrm{SA} \mathrm{v}$ & A v D & $\mathrm{SA} \mathrm{v}$ & $A v D$ & SA v & A v D & SA v & A v D & $\mathrm{TM} \mathrm{v}$ & JR v \\
\hline \multirow{3}{*}{ Culture } & \multirow{3}{*}{ Aus - Chi - Oth } & $\mathrm{D}$ & & $\mathrm{D}$ & & $\mathrm{D}$ & & $\mathrm{D}$ & & $\mathrm{TL}$ & $\mathrm{TL}$ \\
\hline & & 0.82 & 0.11 & 0.51 & 0.24 & 0.03 & 0.03 & 0.31 & 0.27 & 0.01 & 0.00 \\
\hline & & $(0.99)$ & $(0.91)$ & $(0.97)$ & $(0.94)$ & $(0.91)$ & $(0.92)$ & $(0.96)$ & $(0.96)$ & $(0.86)$ & $(0.91)$ \\
\hline
\end{tabular}




\begin{tabular}{|c|c|c|c|c|c|c|c|c|c|c|c|}
\hline \multirow[t]{2}{*}{ Gender } & $\mathrm{F}-\mathrm{M}$ & 0.00 & 0.01 & 0.43 & 0.32 & 0.00 & 0.00 & 0.09 & 0.41 & 0.65 & 0.09 \\
\hline & & $(0.30)$ & $(0.39)$ & $(0.80)$ & $(0.76)$ & $(0.24)$ & $(0.31)$ & (0.68) & $(0.87)$ & (1.14) & (0.74) \\
\hline \multirow[t]{2}{*}{ Year of study } & $1-2-3$ & 0.55 & 0.95 & 0.68 & 0.71 & 0.00 & 0.01 & 0.00 & 0.00 & 0.01 & 0.02 \\
\hline & & (1.16) & $(1.02)$ & (1.09) & $(0.93)$ & (1.90) & $(1.51)$ & (1.64) & $(1.42)$ & (1.77) & (1.34) \\
\hline \multirow{2}{*}{$\begin{array}{l}\text { Accounting } \\
\text { major }\end{array}$} & Yes - No & 0.62 & 0.75 & 0.61 & 0.56 & 0.05 & 0.20 & 0.08 & 0.02 & 0.49 & 0.23 \\
\hline & & (1.44) & $(1.26)$ & $(0.77)$ & $(0.75)$ & $(0.42)$ & $(0.63)$ & $(0.45)$ & $(0.48)$ & $(0.67)$ & $(0.68)$ \\
\hline \multicolumn{2}{|l|}{$p$-value of } & \multicolumn{2}{|c|}{0.001} & \multicolumn{2}{|c|}{0.696} & \multicolumn{2}{|c|}{0.000} & \multicolumn{2}{|c|}{0.003} & \multicolumn{2}{|c|}{0.000} \\
\hline \multicolumn{12}{|l|}{ Model } \\
\hline \multicolumn{12}{|l|}{ Goodness of } \\
\hline \multicolumn{12}{|l|}{ Fit } \\
\hline Pearson & & \multicolumn{2}{|c|}{0.001} & \multicolumn{2}{|c|}{0.001} & \multicolumn{2}{|c|}{0.000} & \multicolumn{2}{|c|}{0.309} & \multicolumn{2}{|c|}{0.003} \\
\hline Deviance & & \multicolumn{2}{|c|}{0.013} & \multicolumn{2}{|c|}{0.014} & \multicolumn{2}{|c|}{0.000} & \multicolumn{2}{|c|}{0.234} & \multicolumn{2}{|c|}{0.006} \\
\hline
\end{tabular}

Logistic regression results for differences between student responses by culture, gender, years of study and intended major.

The regressions that were not significant are for the students' agreement with the two statements: that they are prepared for dealing with ethical issues in the workplace, and that they are familiar with ethical standards expected of the profession. Whilst we obtain significant results for univariate analyses of the associations between each of the students' characteristics and their agreement with these two statements, these are not reported or discussed because the corresponding multivariate results are not significant.

Overall, the majority of students agreed with all of the statements. When the "agree" and "strongly agree" responses are added, there is a consensus view that the study of ethics is relevant to an accounting degree, that they are prepared for dealing with ethical issues that they will face in the workplace, and that they have been encouraged by their university accounting education to think about the ethical implications of accounting and auditing practices. There is less agreement that they are familiar with the ethical standards expected in the profession.

Analyzing the differences in responses by student characteristics, their cultural background and their gender are associated with their agreement or strong agreement that the study of ethics is relevant to an accounting degree. The students who are most likely to strongly agree are male, and those from cultural backgrounds other than Chinese/Hong Kong or Korean. When students were asked if their university education encourages them to think about the ethical implications of accounting or auditing, the students most likely to strongly agree are male, and those at earlier stages of their degree. A non-Australian cultural background is more likely for those who strongly agree than those who disagree. Therefore, the characteristics most strongly associated with students' views on the study of ethics are their cultural background, their gender and their credit points completed.

Finally, when asked about their experience of studying ethics, the students who are most likely to report that there is too little emphasis in their accounting units (15.45\%) are male, and those at later stages of their degree. Those who are most likely to think that there is too much emphasis on ethics $(6.52 \%)$ are female, and those from non-Australian cultural backgrounds. Therefore the characteristics most strongly associated with students' (dis)satisfaction with the amount of ethics studied at university are cultural background, gender and credit points completed.

Students from cultural backgrounds other than Australia generally have lower rates of strong agreement with these statements, which may reflect a view that the role of the university is to provide them with technical rather than ethical education. However this needs to be considered in conjunction with the students' views on the emphasis on ethics in the degree. It may also reflect that this is an area in which they struggle to perform at high levels, due to the non-technical nature of ethics-related material.

To the extent that our survey findings are generalisable, we believe they show that: (i) students in early stages of accounting programs have a pre-existing ethical orientation (by which we mean pre-existing ethical ideas and opinions) that is acquired from long-standing sources-family, culture and religion-more so than from 
relatively recent sources, (Note 9) such as professional/work-related experience and university study, which is typically of only short duration; (ii) the proportions of these long-standing sources vary significantly between cultures and between genders; that (iii) as students progress through their study programs, the influence of more recent professional/work-related and educational sources increases and the influence of the longer-standing sources decreases; but that most importantly, (iv) the dominant or most influential source of students' ethical ideas and opinions continues to be these long-standing sources.

\section{Discussion}

Existing research suggests that heightening accounting students' awareness of the ethical demands of accounting is both an achievable aim and that accounting educators can approach the implementation of IFAC's recommended three-stage approach to ethics education with a fair degree of confidence. In the context of a culturally mixed student cohort, we suggest that this requires engagement with students in a manner that takes seriously the ethical ideas and opinions they have already formed prior to their accounting studies.

As noted previously, the IFAC-commissioned Ethics Education Toolkit, developed as a resource to assist IFAC member bodies implement the three-stage approach to ethics education, suggests a single curriculum is not suitable for all groups of students. Our survey findings confirm that "cultural factors play a part in the way students perceive and deal with problems" (Cooper et al., 2008, p. 416), but we are not as pessimistic as the authors about the usefulness of their approach in more diverse contexts, when they state: "the extent to which differences exist is likely to impede the effectiveness of the Toolkit" (ibid). We believe that with some modification the three-stage approach can be effectively implemented in a culturally sensitive and inclusive manner to a mixed student cohort.

Our survey's over-arching finding that long standing sources of ethical ideas and opinions-family, culture and religion - are influential throughout students' university study, suggests that accounting educators, at universities (like ours) with mixed student cohorts, need to implement ethics education in ways that acknowledge that students come from a range of backgrounds, have varying expectations and engage with ethics-related material throughout their study in differing ways (see also Capra, 2002; Young \& Annisette, 2009).

Our suggestions for increasing the cultural sensitivity and inclusiveness of the three stage approach across each of the introductory, middle, and late stage pre-qualification education are framed and supported by Carlin and Strong's (1995) three recommendations. Carlin and Strong (1995, p. 389) suggest that educators need to (i) recognize the existence of cultural differences within the ethical dimension of decision-making, (ii) frame ethical enquiry to encompass cultural diversity without assumptions of moral or intellectual superiority, and (iii) find ways to make concrete connections between ethical theories and the actual demands of ethical decisions in professional practice $(1995$, p. 389).

In the following, we describe how the views we draw on above, from Carlin and Strong, can be practically applied to IFAC's three-stage approach. As we will explain, the key to practical application is focusing accounting ethics education on the ethical demands of accounting practices themselves - as discussed with and by students - more so than specific qualities that individual moral agents should possess as articulated from the perspective of a single ethical/cultural tradition.

\subsection{Stage 1-Teaching Traditional Theories}

Recall that IFAC recommends the prequalification accounting program to focus on accounting students' acquisition of ethical knowledge in Stage 1, which includes the teaching of traditional ethical theories developed and articulated within the Western philosophical tradition.

Our survey results show that long standing sources of ethical ideas and opinions-family, culture and religion - are influential throughout students' university study. Accordingly, we recommend Stage 1 teaches ethical theories and perspectives quite specifically as an introduction to discussing and acknowledging differing ethical orientations and perspectives. Although we believe that familiarity with traditional Western ethical theories will assist students to reflect upon and articulate their own ethical views, we recommend that alternative non-Western perspectives are also offered. This means broadening the outline of Stage 1 so that both Western and non-Western ethical theories and perspective are included, along with discussion of the range of factors - family, culture and religion - that influence individual ethical opinions and ideas.

The purpose of a broader introduction at Stage 1 is to (i) introduce students to the discussion of ethical ideas and opinion in light of the fact that ethical opinions and ideas can differ, and (ii) introduce students to the ways that ethical opinions, ideas and decisions are informed by a range of factors. The purpose here is not to suggest that ethical opinions and ideas are all equal or equally unproblematic, as per subjective relativist or cultural relativist 
ethical theories. (Note 10) Instead, the purpose of introducing students to a range of theories and perspectives is to discuss with students how ethical opinions, ideas and decisions may be challenged, or indeed appear unjustified, from other perspectives and traditions, and indeed from within traditions. (Note 11)

Stage 1 is foundational for the discussions of ethics at Stages 2 and 3, but it does not need to be integrated with the technical content of the early stage accounting curriculum. For this reason we believe it can be delivered as a stand-alone topic, and that staff from other discipline areas, such as philosophy, can be involved in developing content and in delivery. (Note 12)

\subsection{Stage 2-Ethics in Accounting Contexts}

In Stage 2, IFAC recommends that ethical issues are introduced as they apply within accounting contexts, with the aim of raising students' sensitivity to the ethical dimensions of professional practice while applying the theoretical content delivered in Stage 1. For this reason, we recommend integrating ethics within existing accounting subjects in Stage 2, rather than keeping the discussion of ethical issues to either a discrete ethics subject or to discrete ethics topics within a few subjects. We suggest frequent and informal discussion of the ethical demands and challenges that are directly connected to accounting theories, practices and techniques, doing so in ways that acknowledge the differences in ethical perspectives and orientations introduced in Stage 1.

At Stage 2 the discussion of ethics should be explicitly normative and apply directly to accounting practices and techniques and their application in concrete circumstances. It should not be a theoretical or general discussion, as per Stage 1. This requires engaging students with ethical questions as part of the teaching of accounting theories, practices, and techniques, for example: asking students to consider how particular decisions accord with their own values and why; asking students to consider whether particular decisions are fair/accountable/responsible; and, asking students what they mean when they use these words. Questions need to be direct, for example: asking students to consider what is the most honest way to represent a particular set of financial results; asking students to consider whether a course of action is in the interest of one set of stakeholders, but not in the interests of others; and, asking students why they think this either does or does not matter.

We believe the challenge for accounting educators at Stage 2 is to genuinely integrate the ethical dimensions of accounting into a teaching dialogue with students, so that raising and discussing ethical questions is not perceived as either an add-on or optional element of accounting practices.

\subsection{Stage-Complex Cases}

In Stage 3, the learnings in the two previous stages are brought together in more complex or situated cases. We suggest that the best way to raise awareness of the often subtle ethical dimensions of accounting is the frequent use of case studies in Stage 3. Case studies should be open-ended, aimed at identifying issues rather than solving problems, or promoting a single approach to the ethical dimensions of cases. Students should practice structuring and clearly articulating their own views of the ethical dimensions of cases, their own responses to them, and the ways in which their responses can be challenged and, in turn, defended.

Here the aim is to provide students with opportunities for encountering ethical perspectives, arguments and conclusions that differ from their own, and possibly provoke and challenge their own. Case studies need to be drawn from a variety of cultural contexts to take account of the diversity of students' backgrounds and experience, and to illustrate the manner in which ethical issues and problems present differently in different contexts. Students' prior experiences (e.g. a family business and work experience) can be drawn on to facilitate ethical discussion and reflection. By their final year, many students are already involved in a workplace, providing them with concrete exposure to accounting issues and professional standards. Where possible, students should be encouraged to discuss the ethical dimensions of their own professional experience.

At least $75 \%$ of the students who responded to our survey learn accounting, and thus study ethics, in a language other than their first or home environment language. We believe this may affect the readiness of these students to explore and articulate ethical ideas and opinions in class discussion and in written formats. The issue of language familiarity provides challenges in all areas of accounting education when teaching a mixed student cohort, but provides a particular challenge when dealing with the ethical dimensions of case studies due to the need for confident language expression and the ability to articulate subtle distinctions. We suggest this be addressed with group work projects and group discussions in which students' ideas, opinions and feelings can initially be freely expressed in students' first languages.

Over and above encouraging the discussion of ethical positions, the translation of ethical positions between familiar and less familiar languages directly engages students with the suffusion of cultural influence within each language, and highlights the fact that the communication of ethical positions requires sensitivity to the languages 
and idioms of work settings and cultural contexts. This can only be of benefit to students who are entering an increasingly globalised business environment.

\section{Concluding Remarks}

We support IFAC's directives and recommendations to include ethics education within pre-qualification accounting education programs. However, we believe that in the context of culturally mixed student cohorts who will work in an increasingly globalised business environment, the issue of cultural sensitivity and inclusivity of accounting ethics education deserves further attention. We have recommended that a broad and inclusive introduction to ethics is needed at introductory levels of accounting study, one that acknowledges a range of perspectives. We have also recommended that beyond introductory level study, ethics needs to be integrated within accounting subjects - as part of accounting theories, practices and techniques-rather than being presented within stand-alone ethics subjects, or as stand-alone ethics components within subjects. We recommend the integration of ethics within accounting subjects needs to be done in ways that (i) increase students' awareness of the ethical dimensions of all aspects of accounting practice, (ii) deepen students' understanding of their own and others' ethical values and perspectives, and (iii) provide students with opportunities to engage with the ethical demands and challenges of accounting practices in ways that are considered and reflective, as well as culturally sensitive and inclusive.

Our student survey and teaching recommendations provide a starting point for increasing the cultural sensitivity and inclusiveness of ethics education for accounting students. Future steps will develop quality curriculum materials for ethics at introductory levels, and determine effective ways to include ethics content within technical accounting subjects so that ethics is neither tokenistic, nor add-on. This will raise further research questions as to how student engagement with the ethics components of accounting subjects can be assessed, and indeed, if ethics is fully integrated within those subjects, whether such engagement can be separately assessed at all.

\section{Acknowledgements}

The authors are grateful to Professor Catriona MacKenzie of the Department of Philosophy at Macquarie University for her invaluable contribution to the project and advice on earlier drafts of the paper. We gratefully acknowledge the financial support of a Macquarie University Strategic Curriculum Development Grant and the participation and co-operation of staff and students at Macquarie University and Sydney Institute of Business and Technology. Useful comments and feedback have been provided by the Macquarie University Faculty of Business and Economics Learning and Teaching Committee, the Reference Group established for feedback on the grant, in particular James Hazelton, and participants at the American Accounting Association's Ethics Symposium, 14th Annual Symposium on Ethics Research in Accounting, Ethics Committee and Public Interest Section, August 2009.

\section{References}

Armstrong, M. B., Ketz, J. E., \& Owsen, D. (2003). Ethics education in accounting: moving toward ethical motivation and ethical behavior. Journal of Accounting Education, 21, 1-16. http://dx.doi.org/10.1016/S0748-5751(02)00017-9

Brien, A. (1998). Professional Ethics and the Culture of Trust. Journal of Business Ethics, 17, 391-409. http://dx.doi.org/10.1023/A:1005766631092

Capra, F. (2002). The hidden connections: integrating the biological, cognitive and social dimensions of life into a science of sustainability. New York: Doubleday.

Carlin, W. B., \& Strong, K. C. (1995). A Critique of Western Philosophical Ethics: Multidisciplinary Alternatives for Framing Ethical Dilemmas. Journal of Business Ethics, 14, 387-396. http://dx.doi.org/10.1007/BF00872100

Cooper, B. J., Leung, P., Dellaportas, S., Jackling, B., \& Wong, G. (2008) Ethics Education for Accounting Students-a Toolkit Approach. Accounting Education: an international journal, 17(4), 405-430.

Craig Keller, A., Smith, K. T., \& Murphy Smith, L. (2007). Do gender, educational level, religiosity, and work experience affect ethical decision-making of U.S. accountants? Critical Perspectives on Accounting, 18, 299-314. http://dx.doi.org/10.1016/j.cpa.2006.01.006

Griffith, S. (2006, May). Daedalean tinkering. Michigan Law Review, 104, 1247-1268. 
International Federation of Accountants. (2007). International Education Practice Statement 1: Approaches to Developing and Maintaining Professional Values, Ethics and Attitudes.

International Federation of Accountants. (2008). International Education Standards 1-8.

International Federation of Accountants. (2010). Retrieved from http://www.ifac.org/ComplianceAssessment/published.php-accessed 22/7/10

Jennings, M. M. (2004, February). Incorporating ethics and professionalism into accounting education and research: a discussion of the voids and advocacy for training in seminal works in business ethics. Issues in Accounting, 19(1), 7-26. http://dx.doi.org/10.2308/iace.2004.19.1.7

Leung, P., \& Cooper, B. (1995, May). Ethical Dilemmas in Accountancy Practice. Australian Accountant, 28-32.

Mac Farlane, B. (1998). Business Ethics and the Idea of a Higher Education. Teaching Business Ethics, 2, 35-47. http://dx.doi.org/10.1023/A:1009757402637

Molyneaux, D. (2004). After Andersen: An Experience of Integrating Ethics into Undergraduate Accountancy Education. Journal of Business Ethics, 54, 385-398. http://dx.doi.org/10.1007/s10551-004-1827-8

Ponemon, L. A. (1993). Can Ethics be Taught in Accounting? Journal of Accounting Education, 11, 185-209. http://dx.doi.org/10.1016/0748-5751(93)90002-Z

Waldmann, E. (2000). Teaching ethics in accounting: a discussion of cross-cultural factors with a focus on Confucian and Western philosophy. Accounting Education, 9(1), 23-35. http://dx.doi.org/10.1080/096392800413636

Wright S., Byers P., Dyball M., Hazelton J., \& Radich, R. (2011). Engaging Staff in Curriculum Change: Reflections from an Accounting Ethics Initiative. Asian Social Science, 7(11), 93-99. http://dx.doi.org/10.5539/ass.v7n11p93

Young, J. J., \& Annisette, M. (2009) Cultivating imagination: Ethics, education and literature. Critical Perspectives on Accounting, 20(1), 93-109. http://dx.doi.org/10.1016/j.cpa.2007.03.003

\section{Notes}

Note 1. Craig Keller et al. (2007) cite a number of studies exploring this theme, most of which are not of accounting students or graduates. Craig Keller et al.'s work, however, does concern accounting graduate and undergraduate students in the United States of America.

Note 2. The survey instrument is available from the corresponding author upon request.

Note 3. Analysis of the responses to the open-ended question is not included in this paper.

Note 4. Students can enter the accounting program at the university in the second year, after successfully completing a program at a feeder college tht is academically moderated to ensure that is identical in content and assessment to the first year program on the main campus. Due to the equivalence of the two first year programs, and the significant number of students who enter the second year program via this route, first year students at the college were also included in the survey to ensure the comparison across credit points completed is not biased due to a change in demographics in the sample. A separate analysis of the responses by students at the feeder college revealed significant differences between their demographics and those of students at the university, thus confirming the decision to include the feeder college students in the survey.

Note 5. Year of study was measured by credit points completed. Students enrol in individual subjects, not program years, and in any semester may undertake subjects across all levels. Year of study is therefore an approximate measure of the level of the subjects undertaken.

Note 6. This question is potentially ambiguous, depending on the definition of home: place of residence in Australia, or country of birth. This ambiguity was not identified by any of the respondents, but was identified by the researchers when analyzing the data.

Note 7. English is the official and predominant language spoken in Australia.

Note 8 . This exposure to the workplace is evident from the demographic data, showing that over $90 \%$ of students are in the workforce from first year.

Note 9. Although this may seem obvious, we believe the point needs to be stressed in connection with ethics education, in order to avoid approaching it as if students start from either a univocal or a neutral perspective. 
Note 10. An extreme cultural relativist position is that no judgment can be made of the ethical dimensions of cultural practices, customs and beliefs beyond one's own, with the implication that no inter-cultural dialogue and agreement is possible. An extreme subjective relativist is that no judgments can be made of the ethical dimensions of another individual's behaviour and choices, with the implication that no interpersonal ethical standards and mores are possible. We do not believe that promoting reflection on individual, cultural and theoretical differences supports either form of relativism.

Note 11. For example, the main ethical theories as articulated within the Western philosophical tradtion (deontology, utilitarianism and virtue theory) provide different answer to the question of how right action is understood.

Note 12. There are potential problems with presenting stand alone topics that accounting students may not see as relevant to their accounting studies. For this reason it is essential that course content is of a high standard that engages students and that assessments are well-designed. 